\title{
EL PROBLEMA DE LA POBLACIÓN EN EL NORDESTE DEL BRASIL: SUS DIMENSIONES ECONÓMICAS E IDEOLÓGICAS
}

\author{
Herman E. Daly * \\ Economic Growth Center, Universidad Yale \\ y Universidad del Estado de Louisiana
}

Los ricos se hacen más ricos y los pobres tienen más hijos.

ANÓNIMO

La mesa del pobre es escasa, pero el lecho de la miseria es fecundo.

ANónIMO

\section{INTRODUCCIÓN}

El NORDESTE DEL BRASIL, con sus 27 millones de personas, superficie de 1.5 millones de kilómetros cuadrados y un ingreso per capita anual de alrededor de 150 dólares, es tal vez el "país" más pobre del hemisferio occidental. ${ }^{1}$ Los esfuerzos por desarrollar la región han tenido lugar durante dos amplias épocas históricas.2, 3 La primera es la época "hidráulica" en la que se puso fuerte énfasis en la lucha contra las inundaciones periódicas, a las que se hacía referencia como la causa principal del atraso. Este período es a veces llamado período DNOCS, por el nombre de la institución principal y más reciente responsable de llevar a cabo políticas hidráulicas (Departamento $\mathrm{Na}$ -

* El autor fue durante el período 1967-68 profesor visitante de Economía de la Fundación Ford en la Universidad Federal de Ceará en el Brasil. Las opiniones presentadas en este trabajo son totalmente de su autor y no reflejan necesariamente las de alguna de las instituciones mencionadas. Todas las traducciones del portugués fueron hechas por el autor.

Debo las gracias a mis estudiantes por muchos debates estimulantes, y al fallecido doctor Ari de Sá Cavalcante por su solicitud y hospitalidad. Expreso también mi agradecimiento por los comentarios recibidos en un seminario de la Fundación Getulio Vargas y a numerosos colegas que leyeron un borrador anterior. De nuevo, mis puntos de vista no reflejan necesariamente los de ellos. Muchas de las ideas discutidas aquí son consideradas también en mi trabajo "Desenvolvimento Econômico e o Problema Demográfico no Nordeste Brasileiro" publicado en la Revista Brasileira de Economia, diciembre de 1968.

[Traducción de Adalberto García Rocha.]

1 Rubens Vaz da Costa, "A 'Festa' do Nordeste", O Povo. Fortaleza, octubre 28 y 29, 1967.

2 Stefan Robock, Northeast Brazil: A Devveloping Economy, Washington, The Brookings Institution.

3 Albert 0 . Hirschman, Journeys Toward Progress, Nueva York, Twentieth Century Fund, 1961. 
cional de Obras Contra a Sêca). La segunda es la época presente de "planeación-capital-tecnología" en la que el énfasis no se pone en las inundaciones (que en ocasiones fueron más bien un chivo expiatorio tanto como un castigo), sino en la baja formación de capital, el atraso tecnológico y la falta de planificación de los esfuerzos por el desarro1lo. Este cambio de énfasis tuvo lugar en el decenio de los cincuenta y marcó el inicio de lo que podríamos llamar el período SUDENE, por el nombre de la institución encargada de estimular y planificar la inversión (Superintendência do Desenvolvimento do Nordeste). ${ }^{4}$ El propósito de este trabajo es argumentar la necesidad (y el principio embriónico) de una tercera época de desarrollo de "política de población" (fundamentalmente control de la fecundidad). De ninguna manera se sugiere que la política de población deba reemplazar los esfuerzos de planificación del capital y la tecnología como tampoco que éstos fueran el reemplazo de la política contra la sequía. Más bien es necesario un cambio de énfasis, porque, aunque la política de población no es obviamente una condición suficiente para el desarrollo, se demuestra en este trabajo que sí es una condición necesaria. SUDENE tuvo una división de estudios de la población en su departamento de recursos humanos, pero fue abolida hace algún tiempo y aparentemente SUDENE tiene, en el presente, poco interés en el problema demográfico. Asimismo, en el curso CEPAL-BNDE sobre la economía del Nordeste, impartido en Fortaleza en 1967, simplemente se hizo caso omiso del tema de la población. En el resumen del curso de 9000 palabras no existe la menor insinuación de que exista algo llamado explosión demográfica - aunque puede uno enterarse de que las invasiones turcas del siglo xv crearon dificultades al comercio europeo (Jornal do Brasil, octubre 27, 1967).

La explosión demográfica ha dado al nordeste del Brasil una tasa natural de crecimiento de la población de alrededor de $3.1 \%$ anual, comparada con alrededor del $3.2 \%$ para todo el Brasil, que está entre las más altas del mundo en poblaciones de tamaño comparable. 5 Esta tasa del $3.1 \%$ resulta del patrón ya familiar de la posguerra, consistente en una tasa de natalidad constante ( 4.7 ó $4.8 \%$ anual), ${ }^{6}$ al lado de una tasa de mortalidad menor o decreciente (1.6 ó $1.7 \%$ anual). ${ }^{7}$

4 Josué de Castro, Sete palmos de terra e um caixão, São Paulo, Editora Brasiliense, 1967.

5 Demografía: diagnóstico preliminar (Plano Decenal de Desenvolvimento Econômico e Social), agosto de 1966 , p. 75 . Demografia da $3.1 \%$ para la década 195060 . Olávo Baptista Filho, Poputação e desenvolvimento, Universidad de São Paulo, 1965, da una cifra de $3.2 \%$ (p. 23). Artur Hehl Neiva cree también que la tasa correcta para el Brasil es "cuando menos $3.3 \%$ y todavía crece. Las agencias gubernamentales han mencionado recientemente hasta $3.5 \%$ ". Neiva, "The Population of Brazil", en Population Dilemma in Latin America, J. Mayone Stycos y Jorge Arias, compiladores, Washington, Potomac Books, 1966, p. 56.

6 Almir Caiado Fraga, Problemas demográficos do nordeste do Brasil, Instituto de Pesquisas Econômicas, Universidade Federal do Ceará, Fortaleza, 1966, p. 24.

7 Anuário estatístico do Brasil, 1966 (IBGE), estimado a partir de los datos de la p. 55. Sólo aparecen las tasas de mortalidad urbanas. Para las tasas de mortalidad urbanas más altas del nordeste del Brasil se tomó como aproximación la tasa de mortalidad general de la región. Esta tasa puede estar sobrestimadá, pero la usaremos de todos modos ya que no existen otros datos al respecto, y la tendencia de la tasa es'a la baja, de modo que si fuera una sobrestimación en la actualidad, no lo sería en el futuro. 
Es probable que la tasa de mortalidad baje con relativa rapidez al nivel de la de São Paulo que es de 0.9 \% como resultado de las vacunaciones masivas, puesto que ni la viruela ha sido eliminada aún. ${ }^{8}$ Por esto, en un futuro próximo la ya elevada tasa de crecimiento seguramente aumentará hasta acercarse al $4 \%$. Históricamente, el Nordeste ha sido região de transbordamento demográfico por excelência, que presenta un balance de migración neto acentuadamente negativo, mientras que las otras regiones muestran balances netos positivos. ${ }^{9}$ Este flujo hacia afuera ha disminuido la tasa neta de crecimiento de la región hasta aproximadamente $2.2 \%$ anual en la década 1950-60.10 En 1872 el Nordeste contenía el $47 \%$ de la población brasileña, mientras que en 1960 contenía sólo el $32 \%$.11 Este cambio está explicado por una mayor inmigración extranjera al sur, así como por una migración interna continua del nordeste al sur, y en menor grado al oeste.

Además del movimiento hacia el sur ha habido una migración tremenda del interior a las ciudades costeras del Nordeste. Mientras que la tasa de crecimiento de $3.1 \%$ duplicará la población de la región en menos de 23 años, las ciudades costeras como Fortaleza, cuya tasa de crecimiento es de $6.6 \%$, duplicarán su población en 10 años aproximadamente..$^{12}$ Cuando consideramos que esta duplicación rápida aumentará seriamente la proporción de pobres, iletrados y jóvenes en las ciudades (debido a las migraciones de iletrados pobres del interior, a la tasa de natalidad mayor de la clase más pobre, y a la tendencia inherente de una tasa de natalidad elevada a rejuvenecer la población) vemos entonces lo que los sociólogos brasileños quieren decir cuando declaran que las ciudades se han "hinchado" más que crecido (cidades inchadas). Más aún, cuando consideramos que este hinchamiento presenta no sólo problemas de urbanización futura de mayor inversión per capita para la infraestructura urbana más que para la rural, de estabilidad política y refuerzo legal, 13 sino que también amenaza romper las condiciones precarias de salud pública y facilita la proliferación de las epidemias, se hace claro entonces que este hinchamiento está constituyéndose en una explosión ecológica.

A pesar de estos hechos, y a pesar del argumento moral de que todo

8 La divergencia de las tasas de mortalidad infantil entre el Nordeste y São Paulo es todavía más sorprendente: 174 por mil contra 70 por mil, respectivamente. (Anuário estatístico do Brasit, 1966, p. 55.)

9 José Francisco de Camargo, "Subsídios para uma política demográfica de possível aplicação ao Brasil", Problemas Brasileiros, Núm. 53, agośto de 1967, São Paulo, p. 23. Ver también' Roland Chardon, "Changes in Geographic Distribution of Population in Brazil, 1950-60", en E. N. Baklanoff, New Perspectives of Brazil, Vanderbilt University Press, 1966. Un mapa informativo que muestra los flujos migratorios aparece en Artur Hehl Neiva, op. cit., p. 53.

10 Demografía..., op. cit., p. 75.

11 Fraga, op. cit., p. 23. p. 252.

12 As migrações para Fortaleza, Govêrno do Estado do Ceará, Fortaleza, 1967,

13 El director de la cárcel pública de Fortaleza (una ciudad de 700000 habitantes) renunció a su cargo debido a que el hacinamiento del Iugar hizo imposible su trabajo. La capacidad de la cárcel es de 180 personas, pero fue amontonada con 353, de los cuales diez padecían tuberculosis. En los seis meses precedentes murieron cinco prisioneros en peleas y las fugas eran cosa de rutina. (Jornal do. Brasil, diciembre 17 de 1967.) 
niño debe ser un hijo deseado, la tasa de crecimiento de la población es tratada corrientemente como una constante semisagrada de la naturaleza, un parámetro, no una variable, en el esfuerzo por el desarrollo. De hecho, la "opinión pública" en el Nordeste es muy hostil a las políticas de población, aunque el control natal es practicado ampliamente por la clase alta. Entender mejor esta situación trágicamente paradójica es uno de los objetivos de lo que sigue en este trabajo. En la sección II consideraremos el aspecto económico del problema de la población, arguyendo objetivamente y con detalle que el control de la población es una condición sine qua non para el desarrollo de la región.* En la sección III profundizaremos en los aspectos ideológicos y polémicos del problema de la población, argumentando que el nacionalismo, la influencia comunista y los intereses a corto plazo de la oligarquía son aún mayores obstáculos a la política de la población que el catolicismo tradicional. En la sección IV se agregan unas cuantas conclusiones. Para hacer más fácil relacionar el caso del nordeste del Brasil con el problema mundial general del control de la población y el desarrollo económico, se hará referencia frecuente a la excelente investigación de la literatura reciente sobre el tema hecho por Goran Ohlin, de la OECD.14

\section{EL ASPECTO ECONÓMICO DEL PROBLEMA DE LA POBLACIÓN}

Para nuestros propósitos sólo necesitamos el armazón analítico más simple para relacionar el crecimiento del ingreso con el crecimiento de la población. La fórmula siguiente convierte la relación HarrodDomar (en la cual se basa el cuerpo de la teoría contemporánea del desarrollo) $)^{15}$ a una base per capita sustrayendo el crecimiento de la población: 1e

$$
r=\frac{s}{k}-p
$$

donde, $r=$ tasa anual de crecimiento del valor de la producción;

$s=$ ahorro neto anual (formación de capital) como porciento de la producción anual;

$k=$ relación capital-producto marginal ;

$p=$ tasa anual de crecimiento de la población.

El cociente $s$ puede ser expresado como $\Delta C / Y(C=$ acervo de capital, $Y=$ producción anual), y $k$ como $\Delta C / \Delta Y$, de modo que $s / k$ se convierte en $\Delta Y / Y$ que es la tasa de crecimiento del ingreso o producto total. De esta manera, la fórmula dice simplemente que la tasa de

* El apéndice es un replanteamiento más riguroso de los puntos de la sección II.

14 Goran Ohlin, Population Control and Economic Development, Development Centre, Organization for Economic Cooperation and Development, París, 1967.

15 Gustav Ranis, "Theories of Economic Growth in Capitalist Countries", en E. A. G. Robinson (compilador), Problems in Economic Development, Londres, Macmillan, 1965, p. 4.

16 C. P. Kindleberger, Economic Development, Nueva York, McGraw-Hill, 1965, pp. $45-46$. 
crecimiento del ingreso per capita es igual (aproximadamente) ${ }^{\mathbf{1 7}}$ a la tasa de crecimiento del ingreso total (expresada como $s / k$ ) menos la tasa de crecimiento de la población. De acuerdo con nuestra ecuación simple un aumento en $r$ puede darse sólo de tres maneras: elevando $s$, reduciendo $k$ o reduciendo $p$. Se argumenta después en este trabajo que las primeras dos alternativas han sido plenamente discutidas, y que en el Nordeste reducir $p$ es la única manera efectiva de aumentar $r$.

Veamos más de cerca cada una de las tres variables.

La reláción $s$ es el porciento ahorrado del ingreso total (en alguna parte) e invertido (en la región), y depende no sólo de la capacidad para abstenerse de consumir, sino también de la capacidad para transferir lo que no es consumido de los que ahorran a los que invierten, lo cual presupone además la existencia de una clase de individuos que invierte el dinero de otros. Cuando el ahorro proviene de fuera de la región esta clase es necesaria a fortiori. Así, $s$ es una relación sociológica que depende de la voluntad y de la capacidad para ahorrar (incluyendo la distribución del ingreso) y de la eficacia de las instituciones financieras que transfieren los ahorros a una clase constituida supuestamente por empresarios, ya sean privados o gubernamentales.

La relación $k$ refleja el estado de la tecnología, la administración empresarial y la disponibilidad de los factores distintos del capital, y la magnitud del uso de éste. El parámetro $k$ es la productividad total del capital (diferencial) más que su producto marginal (derivada parcial). En el primer caso, los otros factores (tierra, trabajo) son libres de ajustarse mientras que en el segundo se mantienen constantes, a medida que se agrega una unidad más de capital. La variable $k$ está medida en años,* siendo esencialmente éste un período de recuperación -esto es, el número de años necesarios para que un dólar de inversión adicional genere una cantidad adicional igual de ingreso nacional. El recíproco de $k$ tiene las mismas unidades que la tasa de interés y puede ser considerado como una "tasa nacional de interés" que expresa la tasa anual de recuperación de los dólares adicionales invertidos, o el porciento del dólar invertido que se recupera en un año. La "tasa nacional de interés" excede a la tasa de interés ordinaria recibida por el capitalista individual en un monto que refleja economías de escala y efectos multiplicadores.

La tasa $p$ ha sido explicada por las teorías biológicas, culturales y económicas, todas las cuales son pertinentes y ninguna completamente satisfactoria. ${ }^{18}$ Tal vez la mejor generalización acerca del crecimiento

17 La fórmula exacta sería $r=\left(\frac{100+\frac{s}{k}}{100+p}-1\right) 100$. Para tasas de crecimiento pequeñas la fórmula más simple da una aproximación más cercana. $* k=\frac{\Delta c}{\Delta y}$ es un cambio en un acervo dividido por un cambio en el flujo, $\frac{\Delta \$}{\Delta \$ / t}=t$, donde $t$ es el tiempo medido en años.

18 Ver Sidney Coontz, Poputation Theories and the Economic Interpretation, Londres, Routledge and Kegan Paul, 1957. 
de la población es la establecida por Ezra Bowen (An Hypothesis of Poputation Growth): "El tamaño de la población tiende a variar en relación directa con la riqueza agregada, e inversa con la posición del nivel de vida." La primera cláusula es simplemente un replanteamiento de la ley biológica de que toda vida tiende constantemente a hacer presión sobre los medios de subsistencia. Ya que para todos los animales vivientes, excepto el hombre, los niveles de vida son constantes y uniformes, se concluye que mayores medios de subsistencia (riqueza) llevan a cantidades mayores de individuos que existen bajo el mismo nivel de vida. La cualidad única del hombre es que estos niveles de vida no son constantes en el tiempo ni uniformes a lo largo de la población. En la medida en que cada persona disfruta un nivel de vida creciente, o que una clase disfruta de un nivel más alto, entonces menos personas pueden existir sobre cualquier ingreso agregado dado. Veremos que en el Nordeste, la primera cláusula, aquella que se refiere a la población animal, se aplica a la clase más baja, mientras que la segunda cláusula, específicamente humana, se aplica a la clase superior. Para nuestros propósitos no necesitamos llevar más lejos la discusión de las varias "leyes" del crecimiento de la población. Es suficiente notar que estas "leyes" pueden ser alteradas por una política consciente, como Io atestigua la historia de Irlanda, Japón, China nacionalista y otros países.

Aunque nuestra fórmula identifica sólo tres determinantes del desarrollo en términos de producto per capita, cada una de las tres depende a su vez de una gran cantidad de influencias. Los dominios de las variables $s, k$ y $p$ deben ser considerablemente menores que el campo de los números reales, si es que la fórmula ha de tener alguna pertinencia económica; los límites son proporcionados por la miríada de factores socioeconómicos que no entran directamente en la fórmula. Por ejemplo, la psicología y la distribución del ingreso y las instituciones capitalistas son tales que $s$ es generalmente menor que $20 \%$, la tecnología y los hábitos de trabajo son tales que $k$ está usualmente entre 2 y 6 años, y la biología y la "cultura" casi siempre mantienen $p$ entre 0 y $4 \%$. Por ello tiene sentido hablar del "potencial de ahorro", de la "capacidad para absorber capital" o "tecnología" o de los "límites naturales de las tasas de natalidad y mortalidad" bajo ciertos niveles generales o estilos de civilización. En otras palabras, nuestra fórmula simple abarca más cuando tratamos de especificar los dominios de las variables, y a menos que conozcamos algo acerca de estos dominios, no sabremos de lo que estamos hablando.* Lo que quisiera sugerir es que el Nordeste ya está operando a su capacidad para absorber capital y tecnología (que resulta en una elevada tasa de crecimiento), pero está muy lejos de su capacidad para reducir el crecimiento de la población. Más aún, el alto crecimiento de la población es el límite social principal que mantiene baja la capacidad para absorber capital y tecnología, y el potencial de ahorro. Es también el factor que im-

* De otra manera podríamos dejar que $k$ se acerque a cero o que $s$ crezca (aunque no más de $100 \%$ en una economía cerrada) y alcanzar un valor de $r$ tan grande como quisiéramos sin preocuparnos por p. Desde luego, "eliminar" de este modo el problema de la población "elimina" igualmente el problema económico. 
pide que el crecimiento del producto per capita en el Nordeste sea representativo de desarrollo, lo cual hace pensar en una "economía hinchada" a la vez que en ciudades hinchadas.

La relación media capital-producto para la industria ha sido estimada por Hirschman como de alrededor de 2.5.19 Singer da una estimación similar (para 1950) en el estado de Ceará (2.73 para la industria; 2.07 para la agricultura). ${ }^{20}$ La cifra de 2.5 es baja al compararla internacionalmente y refleja el predominio de la industria ligera. Si aumentara la industria pesada es de esperar que dicha relación hiciera otro tanto en el futuro. De acuerdo con Kuznets, ninguno de los diez países desarrollados que él estudió ha tenido en el último siglo una relación marginal capital-producto menor que 3.21 La estimación de Hirschman de 2.5 fue una relación media, de modo que la relación marginal puede ser un poco más elevada. Por otra parte, el crecimiento de la población necesita de inversiones en infraestructura, en escuelas, caminos, habitaciones y servicios públicos, que tienen relaciones capital-producto más elevadas que la agricultura y la industria. Supongamos, entonces, que 2.5 es una estimación razonable, y que esté probablemente muy cercana al límite inferior del dominio de $k$ - esto es, poco factible que $r$ aumente al reducir $k$, o cuando menos no mucho, y no a largo plazo. De hecho, parece probable que $k$ tenderá a elevarse.

Sin embargo, como Lauchlin Currie (Accelerating Development) ha señalado, a menudo es posible extender hacia abajo el dominio de $k$ a través del cambio social relativamente sencillo consistente en alargar el día útil del capital trabajando todos los turnos del día, empleando así el trabajo anteriormente ocioso y elevando la producción de los bienes necesitados. La variable $k$ está medida en años, no horas. Al duplicar el número de horas trabajadas por año reduciríamos $k$ a la mitad de su valor. Además, también reduciríamos a la mitad la relación capital-producto promedio y haríamos efectiva de un golpe la ganancia originada por el aumento en la productividad de unidades de capital intramarginales. Esto supone que el producto extra podría ser vendido, pero si se siguen políticas keynesianas para estimular la demanda agregada esto debería ser posible. Tal política debería ciertamente ser puesta en práctica, pero varias limitaciones nos impedirían esperar mucho de ella en el Nordeste. Primero, algunas industrias ya están trabajando más de un turno. Segundo, la estrategia funciona sólo para el capital físico, no para el capital humano o la mano de obra calificada, que necesita tiempo de ocio. Ello limita la política al capital físico que requiere principalmente mano de obra de baja calificación para su operación. Por desgracia, son el capital humano y la calificación la explicación principal del crecimiento, pero son lo que más escasea en el Nordeste. Tercero, la estrategia es pertinente principalmente en la industria cuya participación en el valor de la producción

19 Albert O. Hirschman, "Desenvolvimento industrial no Nordeste brasileiro e o mecanismo de crédito fiscal do artigo 34/18", Revista Brasiteira de Economia, diciembre de 1967, p. 17.

20 Hans Singer, International Development: Growth and Change, Nueva York, McGraw-Hill, 1964, p. 260.

21 Simon Kuznets, Modern Economic Growth: Rate, Structure and Spread, New Haven, Yale University Press, 1966, pp. 252-56. 
del Nordeste es sólo del $12 \%$. No es generalmente pertinente en la agricultura debido a que las fluctuaciones estacionales de la producción no pueden ser controladas. No lo es generalmente en los servicios ya que este sector depende primordialmente del capital humano. Es dudoso que alargar el día de trabajo del capital físico en la industria sea suficiente para alterar las relaciones capital-producto tan elevadas de las inversiones demográficas en educación e infraestructura que son requeridas por el aumento de la población.

Sin un esquema de contabilidad del ingreso regional nadie puede decir con seguridad cuál es el valor de $s$, pero gracias al ahorro proveniente del Sur bajo la ley 34/18,22 y del exterior, está claro que los fondos de inversión no son un factor limitante. Asimismo la distribución desigual del ingreso y el consumo suntuario de los ricos demuestran aún más la existencia de un ahorro potencial de tamaño considerable. $E 1$ hecho de que el límite sea la capacidad para absorber lo manifiesta el retardo de 2 a 3 años entre la disponibilidad de los fondos $34 / 18$ y su desembolso. ${ }^{23}$ (Como los fondos no utilizados durante tres años pasan al tesoro federal, la existencia de fondos no utilizados es, en sí, un estímulo a la búsqueda de colocación para aquéllos.) En una entrevista con diez economistas del Banco del Nordeste, la opinión de que en la zona el obstáculo es la capacidad para absorber fondos, y no la falta de éstos, fue unánime. En otras palabras, $s$ está en el límite superior de su dominio. Por ello, si elevar $s$ y disminuir $k$ ya no es medida efectiva para elevar $r$, nos queda reducir $p$ como alternativa última.

Pero tal vez el Nordeste esté creciendo con suficiente rapidez. ¿Cuál es el valor corriente de $r$ ? y ¿por qué el crecimiento no se traduce en desarrollo? Ante la ausencia de una contabilidad regional no podemos hacer más que adivinar el valor de $r$. La mejor fuente de información es el Banco del Nordeste cuyo presidente, Rubens Costa, publicó algunas cifras para los años 1959-64 que muestran que el crecimiento industrial es de $7.4 \%$ anual, y el agrícola de $6.2 \% .{ }^{24} \mathrm{Si}$ tomamos una media ponderada de estas tasas, utilizando el porciento de producción total industrial estimada (12\%) y la correspondiente en la agricultura (42\%) como ponderaciones, ${ }^{25}$ obtenemos una tasa de crecimiento de alrededor de $6.5 \%$ referente al $54 \%$ del producto generado por la agricultura y la industria. Podemos suponer que el restante $46 \%$ en el sector de servicios aumentó a la misma tasa, lo cual podría estar

22 La ley 34/18 es una medida ingeniosa que concede permiso a todas las personas jurídicas brasileñas para reducir a la mitad sus obligaciones por impuesto sobre la renta con tal de que inviertan la mitad ahorrada en los proyectos del Nordeste aprobados por SUDENE. (Véase la nota 19.) El procedimiento ha tenido mucho éxito.

23 Albert O. Hirschman, "Desenvolvimento...", op. cit., pp. 12-13.

24 Rubens Vaz da Costa, "A 'Festa' do Nordeste", op. cit. Los porcientos agrícolas se calcularon a partir de los índices dados, $y$ se refieren a los productos tanto agrícolas como pecuarios.

Una fuente anterior encuentra que la agricultura del Nordeste (excluyendo los productos pecuarios) aumentó su producción a una tasa media anual de $5 \%$ durante el lapso 1950-60. Este aumento se atribuye al uso de más tierras y mano de obra, y la productividad permaneció constante. (Delfim Netto, Antonio Pastore, Eduardo Carvalho, Agricultura e desenvolvimento no Brasil, Estudos ANPES, Núm. 5, São Paulo, 1966, pp. 70-76.

25 Ibid. 
errado en exceso, ya que los servicios incluyen el gobierno y el sector burocrático. No obstante, para el Brasil en su conjunto el valor monetario de la producción de los sectores primario y secundario creció en algo así como un $3.5 \%$ entre 1962 y 1964, mientras que el valor de la producción del sector terciario creció alrededor de 3.2.26 Suponiendo que no hay efecto diferencial de la inflación, nuestra hipótesis de crecimiento igual queda verificada algo burdamente en lo que se refiere al país como un todo, y no parece descabellada para el Nordeste. Si la cifra de $6.5 \%$ es correcta, entonces el ingreso per capita creció al $3.4 \%$ (6.5-3.1) o al 4.3\% (6.5-2.2) al corregir por la emigración.

Una comprobación parcial de estas estimaciones es ver qué valor de $s$ implican. Al sustituir en la fórmula

$$
\left(3.4=\frac{s}{2.5}-3.1\right)
$$

resulta un $s$ de alrededor de $16 \%$. Como ya se indicó, no se cuenta con estimaciones regionales de $s$, pero para Brasil es de alrededor de $15.7 \%$ en el lapso 1961-64.27 $\mathrm{Si}$ suponemos que la tasa de formación de capital en el Nordeste se ha puesto a la par del promedio nacional, entonces todas nuestras cifras son consistentes. Hay un "si" de más, pero no es un "si" del todo irracional, y podemos concluir que el orden de magnitud es correcto y que la tasa de crecimiento del producto está entre 6 y $7 \%$, y esto es todo lo que necesitamos. Una tasa menor daría fuerza adicional a argumentaciones futuras, mientras que una tasa más alta sólo debilitaría ligeramente nuestras conclusiones. Una tasa de 6 a $7 \%$ no sólo es alta comparada internacionalmente, sino que también es más elevada que la tasa de crecimiento de todo el Brasil, en cualquier año del período de posguerra. ${ }^{28}$ Nuestro supuesto de que esta tasa será sostenida es por lo tanto optimista.

Parece entonces que en el Nordeste el ingreso total está elevándose mucho más rápidamente que la población. (Aunque para todo el Brasil sucede lo contrario, ya que durante 1960-64 la producción creció al $2.1 \%$ mientras que la población al $3.1 \%$.) 29 Pero antes de regocijarnos de la posibilidad de que el ingreso per capita regional crezca al $3.4 \%$ (muy por encima de la meta del $2.5 \%$ fijada en Punta del Este) y de concluir apresuradamente que la explosión demográfica no es una amenaza especial para la región, hagamos una pausa para indagar lo que hay detrás de estos promedios engañosos.

Con una distribución del ingreso tan dispar como la del Nordeste, la media aritmética del ingreso de la población es tan sólo un número que, aunque puede representar una meta o una posibilidad, no describe una tendencia central. La mayoría enorme de la gente tiene ingresos muy por debajo del promedio, y muy pocos tienen ingreso muy por encima de aquél. El ingreso modal es un índice más adecuado de tendencia central o "representatividad", y no hay evidencia de que

26 Conjuntura Econômica, Fundação Getúlio Vargas, septiembre de 1967.

27 Ibid. (Calculado como el cociente entre la formación neta de capital y el producto interno neto.) 
el ingreso modal haya aumentado. No conozco a alguien que sostenga que dicho valor crece actualmente, y no hay buenas razones para creer que la familia típica de las clases más bajas (que serían la moda estadística de toda la población) haya mejorado su situación. En primer lugar, el ingreso total de estas clases con seguridad crece con más lentitud que el ingreso total de las clases superiores (o que el ingreso total de ambas), ya que la clase más baja es más castigada por la inflación, no tiene educación o poder de reclamación, y "se necesita dinero para hacer más dinero". Esto último es cierto especialmente ya que la ley $34 / 18$ en realidad viene a significar que los nordestinos que tienen dinero pueden movilizar fácilmente más dinero - $\mathrm{el}$ multiplicador de crédito es de alrededor de 6, y al combinar los fondos de SUDENE con los de las agencias de desarrollo estatales, puede llegar a ser hasta de 16. Pero aun cuando los ingresos totales de ambas clases crecieran al $6.5 \%$, el ingreso per capita de la clase baja (que es una aproximación muy buena al valor modal y por ello es representativo de la tendencia central) permanecería igual, mientras que el de la clase superior se duplicaría. Esto resulta del hecho de que una familia completa de las clases superior y media tiene alrededor de 4 hijos, mientras que una familia de la clase baja tiene alrededor de $8 .{ }^{30}$ La familia de la clase alta, con una tasa de reproducción de 2, duplicaría entonces su número en cada generación * (cada 25 años). El ingreso de ésta, que crece al $6.5 \%$ anual, se duplicaría cada 11 años, o bien cada media generación. Por lo tanto, el ingreso de una generación completa se cuadruplicaría mientras que la población se duplicaría, lo cual quiere decir que el ingreso per capita de la clase alta se duplicará en una generación aproximadamente. Para el caso de la familia típica de clase baja la tasa de reproducción de 4 implica que la población se cuadruplica en cada generación. ${ }^{31} \mathrm{El}$ ingreso, al crecer a la misma tasa de $6.5 \%$, también se cuadruplicaría en 22 años, que representa más o menos una generación, por lo que el ingreso de las clases bajas permanecería constante. Al recordar que el ingreso de la clase baja seguramente crecerá a una tasa algo menor que el promedio de $6.5 \%$, parece muy posible que los ingresos per capita de esta clase tengan tendencia a disminuir - lo cual puede ser

30 No existe información censal sobre esto, pero estas cifras son estimaciones del doctor Galba Araújo, presidente de BEMFAM (Bem-estar familiar) de Ceará. Las cifras fueron corroboradas en conversaciones con varios ginecólogos de Fortaleza. Aunque el promedio para la clase más baja se ha estimado ser alrededor de 8 , las familias con 15 y 20 no son poco comunes. El mismo patrón de fertilidad relativa también se observa entre las naciones ricas y las pobres; las primeras tienen tasas de reproducción de alrededor de 1.5 y las segundas alrededor de 3.0 (Ohlin, op. cit., p. 15). Véase también el Population Bulletin de agosto de 1958, Núm. 5, "Latin America: The Fountain of Youth Overflows", p. 94, que muestra para la parte rural de São Paulo estimaciones de 4.1 niños para hombres de más de 50 años en profesiones liberales, y 7.6 niños para hombres de la misma edad en la agricultura.

* Una generación es igual a la edad media de las madres en la fecha de nacimiento de sus hijos.

31 Al corregir por no casados y defunciones antes de la edad reproductiva, la relación de reproducción de cada grupo sería algo menor que la de la familia típica. La tasa de reproducción del Brasil se ha estimado ser de alrededor de 3 (Camargo, op. cit., p. 17). Es difícil interpretar esta cifra ya que no se especifica el intervalo de tiempo de la generación. 
causa de la emigración de los pobres. Ya que éstos viven a un nivel cercano al de "subsistencia", la "elasticidad de la migración" con respecto a la disminución del ingreso debe ser alta, aunque hay ciertamente otras causas de migración aparte del ingreso decreciente. Estos cálculos no pretenden alcanzar gran exactitud o refinamiento demográfico, pero son suficientes para establecer el fuerte supuesto de que en el nordeste del Brasil "los ricos se hacen más ricos y los pobres tienen más hijos". Las consecuencias sociales de este dictum venerable merecen, por mucho, más énfasis que el puesto usualmente en ellas. Además, de lo anterior se deriva que la proporción de la población que deviene cada vez más rica se hace simultáneamente más poca y que la que tiene hijos se hace cada vez mayor - esto es, la población está siendo "proletarizada". (Véase el apéndice.)

Por añadidura, el enfoque de sentido común del argumento anterior corresponde muy bien con el modelo de desarrollo con oferta ilimitada de mano de obra de W. Arthur Lewis.32 Lewis explica el crecimiento como el resultado del cambio tecnológico y especialmente de la acumulación de capital resultante de una elevación de la tasa de ahorro de alrededor de $5 \%$ a cerca de $15 \%$. Este aumento es posible debido a la creciente concentración del ingreso hacia el sector capitalista (el único sector que ahorra), cuya existencia es a su vez posibilitada por la tasa de salarios reales constante originada por la oferta ilimitada de mano de obra. Sin embargo, en el modelo de Lewis se presupone que la mano de obra excedente será absorbida ulteriormente y que los salarios reales se elevarán, mientras que para el caso del Nordeste la mano de obra ilimitada parece ser una condición permanente asegurada por la reproducción ilimitada del proletariado. Aun con una tasa muy respetable de $6.5 \%$ no se inicia un proceso de suspensión de la proletarización de la población. Lewis supone también que la tasa de salarios del sector capitalista debe ser superior (como en $30 \%$ ) al ingreso per capita (producto medio) en la agricultura de subsistencia para inducir la migración a la ciudad (sector capitalista). Esta diferencia no es necesaria en el Nordeste ya que la migración a las ciudades se ha presentado a una tasa superior a las necesidades del sector capitalista. Aparte de estas dos excepciones, el Nordeste corresponde muy bien al modelo de Lewis, con SUDENE jugando el papel de estimulante del sector capitalista.*

Ciertamente parece necesaria una política de población si es que las masas han de participar de los beneficios del crecimiento. Pero ¿no sería posible aumentar la capacidad para absorber capital y tecnología, y por lo tanto aumentar $s$ y $r$ ? Ciertamente, pero sobre todo lo demás esto requerirá educación, y un crecimiento elevado de la población aumenta la proporción de hijos, lo cual arroja una carga mayor sobre el sistema educativo ya insuficiente, a la vez que aumenta la tasa de dependencia, lo cual hace más difícil el ahorro. Ésta era la situación en 1960 cuando en el Brasil el $43 \%$ de la población tenía

32 W. Arthur Lewis, "Economic Development with Unlimited Supplies of Labor", The Manchester School of Economic and Social Studies, mayo de 1954.

* Las implicaciones internacionales de la reproducción ilimitada en algunos países y la reproducción limitada en otros, sería análoga, como en el caso del modelo de Lewis, a los efectos diferenciales de clase dentro del país. 
menos de 15 años (en comparación con $30 \%$ en Argentina y Estados Unidos y $22 \%$ en Suecia), y el porciento puede ser más elevado en el Nordeste, en vista de sus tasas de natalidad y de mortalidad mayores, aunque las tasas de mortalidad infantil tiendan a reducir la relación de dependencia.33 En 1920 los alfabetos (de 15 años y más) representaban el $14.2 \%$ de la población del Nordeste; el $15.4 \%$ en 1940 ; el $17.7 \%$ en 1950 , y el $15.4 \%$ en $1960 . .^{34}$ En otras palabras, el alfabetismo ha sido aproximadamente constante en los últimos cuarenta años, y de hecho ha declinado desde 1950. Los esfuerzos de alfabetización fueron frustrados por el aumento de la población. Este fenómeno es aún más grave en las ciudades debido a la inmigración de analfabetos del interior. En Fortaleza, la tasa de alfabetismo (para el grupo 5-14) declinó de $57.6 \%$ en 1940 a $39.4 \%$ en 1950 , y probablemente ha declinado todavia más desde $1950 .{ }^{35}$ Kuznets se hace simplemente eco del conocimiento común cuando nos recuerda que "el uso difundido de la tecnología científica es imposible sin una población alfabeta". ${ }^{36}$ A pesar de lo anterior el presupuesto federal para la educación ha disminuido de $11 \%$ del total en 1965 a $7.7 \%$ en $1968.37 \mathrm{La}$ capacidad para absorber capital y tecnología depende principalmente de la calidad de la población, no de la cantidad. Ya que los aumentos en cantidad tienen costos de oportunidad en términos de la calidad de la población, dichos aumentos tienden a mantener baja la capacidad para absorber capital y tecnología, y de allí a mantener bajos $s$ y $k$.

Además de poner nuestra atención en los dominios de las variables, debemos también buscar "entre bastidores" las interrelaciones que no aparecen evidentes en nuestra fórmula simple. Dos relaciones de esa índole nos vienen a la mente. Primero, $k$ está influida por la disponibilidad de los factores distintos al capital, de modo que si la oferta de mano de obra fuera de poca magnitud, un valor de $p$ elevado significaría facilitar (con el tiempo) la reducción del factor trabajo, lo cual haría posible una disminución de $k$. Sin embargo, como en el Nordeste la fuerza de trabajo es superabundante podemos desechar esta posibilidad. En segundo lugar, y esto es de la mayor importancia, una magnitud de $p$ elevada da impulso estructural a la inflación, por lo cual la inversión se canaliza a alternativas más especulativas y menos productivas (elevación de $k$ ), y quizá tiende también a mantener bajo el ahorro (reducción de $s$ ), y ambas circunstancias tendrían un efecto negativo sobre $r$. Es posible, desde luego, que la inflación aumente el valor de $s$ al provocar una concentración mayor del ingreso, pero ésta es de cualquier modo una influencia desafortunada. El impulso estructural a la inflación provocado por un valor de $p$ alto se produce de dos maneras. Una de ellas, un valor alto de $p$

33 Demografia: diagnóstico preliminar, op. cit., p. 50.

34 Rubens Vas da Costa, "Rubens Costa depõe sôbre o controle da natalidade", o Povo, Fortaleza, diciembre 9 y 10, 1967. La exactitud en la primera decimal es seguramente inválida.

135 As migrações para Fortaleza, op. cit., p. 29.

36 Simon Kuznets, "International Differences in Income Levels", in Okun y Richardson (compiladores), Studies in Ecomomic Development, Nueva York, Holt, Rinehart, and Winston, 1961, p. 19.

37 Journal do Brasil, editorial, diciembre 12, 1967. 
(junto con una tasa de natalidad elevada) se traduce en que las cohortes jóvenes dependientes agregan anualmente más gente que las cohortes productivas de edades superiores. Por ello la demanda (o la necesidad) de satisfactores tiende a crecer más aprisa que la producción o la oferta. Este efecto-edad es reforzado por la tasa de reproducción más elevada de la clase baja necesitada y menos productiva. También este proceso es coadyuvado por el sistema fiscal ya que el aumento del número de individuos dentro de las cohortes contribuyentes es menor que el aumento numérico en las cohortes que demandan o necesitan los servicios públicos tales como escuelas, salud pública y bienestar. Lo más probable es que el gobierno se vea forzado a funcionar con un déficit inflacionario.*

El problema de la población se torna más agudo cuando uno se da cuenta de que en todos los países desarrollados la agricultura ha sido "desempleadora" de mano de obra a medida que dicho sector se hace más productivo. La existencia de excedentes de personas y salarios bajos hace del avance técnico en la agricultura algo antieconómico a corto plazo, y se reduce así la formación de excedentes agrícolas grandes sobre los cuales depende, en última instancia, el proceso de industrialización. Además, en la industria misma existe la tendencia a incorporar tecnologías nuevas altamente automatizadas con lo cual este sector ofrece una cantidad de empleo pequeña y para la gente educada. Como la mano de obra de los próximos veinte años ya ha nacido, el problema no se aliviará durante algún tiempo mediante el control de la natalidad. Esto difícilmente constituye un argumento en contra del control de la natalidad, aunque en ocasiones se menciona en ese contexto; más bien significa que el control de la población debería haberse iniciado hace veinte años. También, no debemos olvidar que a nivel individual hay un beneficio inmediato $e$ inestimable para la clase baja, derivado del control de la natalidad. Decir que los padres de diez hijos desean realmente tener cinco más, es, parafraseando a Marx, calumniar a la raza humana. También la tasa de mortalidad infantil en el Nordeste, que sobrepasa 174 por mil (contra 70 en São Paulo), ${ }^{38}$ habla en favor de la importancia, tanto en las familias como en las poblaciones enteras, de lo que Boulding ha llamado "el teorema perfectamente lúgubre" de la economía, o sea que si nada se hace para controlar los nacimientos el resultado último de cualquier aumento en la productividad será permitir que más gente (el ejército de reserva de la infancia falleciente) subsista al mismo nivel miserable, aumentando así el total de la miseria humana.39

Si se aceptan los beneficios de la política de población, ¿cuáles son los costos, y es dicha política realmente factible en el nordeste del Brasil? Stephen Enke calcula que con los márgenes presentes, los fondos gastados en el control de los nacimientos en un país subdesarrollado son algo así como 100 veces más efectivos para elevar el

\footnotetext{
* Estoy reconocido al profesor Isaac Kerstenetzky por llamar mi atención sobre este punto.

38 Anuário estatístico do Brasil, 1966, p. 55. Con seguridad ésta es una subestimación debida a los nacimientos no registrados. Las estimaciones de la mortalidad infantil en el Nordeste llegan a ser hasta de $50 \%$.

39 Kenneth E. Boulding, The Meaning of the Twentieth Century, Nueva York, Harper and Row, 1965.
} 
producto per capita que los fondos gastados en proyectos de desarrollo convencionales. ${ }^{40}$ Después de revisar críticamente los cálculos de Enke y otros, y los supuestos muy simplificados subyacentes en esos cálculos, Ohlin concluye, no obstante, que:

Sobre lo que vale la pena hacer hincapié es que es difícil llevar a cabo cualquier cálculo de la ganancia económica que resultaría del control de la población que no apunte a beneficios muy espectaculares. Por otra parte, es creencia común que el control familiar puede llevarse con éxito con costos extremadamente bajos, excepto en comparación con las cantidades insignificantes erogadas hasta ahora. El caso puramente económico es convincente - tan lo es que uno queda tentado de decir que el control de la población podría traer la aurora del crecimiento económico sostenido a los países en desarrollo.41

La factibilidad del control de la población en el Nordeste es considerada nula generalmente, y uno de los pocos estudios demográficos de la región descarta la posibilidad como "todavía muy remota".42 No obstante, la práctica de la planificación de la familia está muy difundida entre la clase alta, y decir que los pobres no desean este tipo de control coincide con la verdad en el mismo sentido que cuando se dice que no "desean" ir a la escuela. Estudios recientes indican que en la zona urbana del Brasil más del $93 \%$ de las familias con 3 o más hijos no desean tener más.43 Otro hallazgo significativo es que en Río de Janeiro el $71.3 \%$ de las mujeres católicas casadas legalmente han utilizado la contracepción antes del cuarto embarazo. ${ }^{44}$ Lo más significativo de todo es la estimación del profesor Rodrigues Lima de que (en los hospitales públicos) fueron tratados 22.3 casos de efectos de aborto inducido por cada 100 nacidos vivos. ${ }^{45}$ Más aún, la mayoría de los abortos inducidos voluntarios suceden fuera de los hospitales. Esta cifra corresponde con resultados de estudios llevados a cabo en Santiago de Chile, donde se encontró que la relación de abortos provocados respecto de los nacidos vivos fue de $23 \%$, y que el $26 \%$ de las mujeres en edad fértil admitieron haber practicado el aborto.46

40 Stephen Enke, "The Economic Aspects of Slowing Population Growth", Economic Journal, marzo de 1966, p. 46. En su forma más cruda el cálculo es el siguiente: una estimación del costo de evitar un nacimiento da alrededor de tres dólares por' año, y el beneficio (la cantidad total en la que aumentan todos los ingresos per capita) sería de aproximadamente un ingreso per capita, o bien de alrededor de 300 ó 400 dólares en la mayoría de los países subdesarrollados. Los cálculos de flujos descontados de costos y percepciones dan resultados similares debido a las elevadas tasas de interés y al hecho de que un individuo no empieza a percibir ingresos hasta alrededor de los quince años. Tales cálculos no dejan de tener cierto valor, pero deben ser interpretados con cuidado.

41 Ohlin, op. cit., p. 120.

42 Fraga, op. cit., p. 22.

43 Bernard Berelson, "KAP Studies on Fertility", en Family Planning and Population Programs, Chicago, 1966. Citado por Ohlin, op. cit., p. 71.

44 Carmen A. Miró, "Some Misconceptions Disproved: A Program of Comparative Fertility Surveys in Latin America", en Family Planning and Population Programs, Chicago, 1966. Citado por Ohlin, op. cit., p. 75.

45 Corrêio da Manhã, julio 9, 1967. El profesor Rodrigues Lima es presidente de BENFAM.

46 Rolando Armijo y Regualda Monreal, "Epidemiology of Provoked Abortion in Santiago, Chile", en Muramatsu y Harper (compiladores), Population Dynamics. Citado por Ohlin, op. cit., p. 69. 
La creencia de que la gente en forma individual no desea el control familiar es un mito.

Para resumir, el nordeste del Brasil debería adoptar una política de población (haciendo hincapié en el control de la natalidad) por las razones siguientes:

1. Sin tal política es improbable que el ingreso aumente (y es probable que decline), lo cual significa que los beneficios del crecimiento no se extenderán a las masas, las cuales constituirán una proporción aún más elevada de la población.

2. Reducirá considerablemente la carga de educar a las masas, lo cual es una precondición para la incorporación de tecnología moderna así como para la democracia. Ciertamente, sin control de la población la proporción de iletrados probablemente seguirá aumentando.

3. Aumentará el potencial de ahorro al disminuir la relación de dependencia.

4. Facilitará la introducción de métodos de productividad elevada en la agricultura, lo cual no es factible ante una situación de excedente de población rural y salarios bajos. Lo mismo es cierto para la automatización de la indust blemas de desempleo tecnológico una vez que los métodos automatizados resulten todavía más económicos que el trabajo de subsistencia.

5. Es necesario evitar que las ciudades hinchadas exploten.

6. La clase baja desea el control natal, aunque no articuladamente, y la clase alta ya lo practica.

7. Un dólar gastado en el control de la natalidad es, según los márgenes corrientes, inmensamente más productivo para elevar el ingreso per capita que un dólar empleado en proyectos de desarrollo convencionales.

8. La región es incapaz de soportar su población presente. De ello son evidencia la emigración, el analfabetismo, las enfermedades y las tasas de mortalidad infantil.

9. Una tasa de natalidad elevada y un valor de $p$ también elevado dan un impulso a la inflación estructural, cuya reacción sobre $k$ y $s$ es desfavorable.

La lista podría ser ampliada pero ya así presenta una argumentación altamente convincente sobre la que uno esperaría un consenso general.* No obstante, la política de SUDENE se ha concentrado en $s$

* Entre los economistas occidentales modernos los puntos de vista más optimistas acerca de la influencia del crecimiento de la población sobre el desarrollo son probablemente los sostenidos por Albert Hirschman y Colin Clark, especialmente este último. Hirschman señala que la calificación desarrollada para enfrentarse al reto de la población es la misma que aquella necesaria para el desarrollo. Esta es una variación muy obvia al tema de "reto y respuesta". La misma observación fue hecha y desarrollada con más detalle por Sir William Temple en 1673 como una explicación de por qué Holanda, más densamente poblada que Inglaterra, era más próspera que ésta (véase $\mathrm{E}$. S. Furni, The Position of the Laborer in a System of Nationalism, p. 139). Lo más importante a notar en la observación de Hirschman es que desde un punto de vista político no se deriva nada de ella. Los países subdesarrollados ya están por mucho en situación de reto y muy lejos de una situación de respuesta - un reto adicional, por ejemplo bombardearlos, no les va a ser realmente de mucha ayuda. Tampoco lo será la explosión demográfica. Hirschman mismo no extrae implicaciones políticas de su afirmación. En el prólogo a su libro Population and Land Use, Colin Clark reconoce que el crecimiento de la población elevado trae dificultades económicas a 
y $k$, y da a $p$ la condición de parámetro. Ellos han tenido éxito considerable en esta estrategia como lo testifican las tasas de crecimiento elevadas del ingreso total y per capita, pero la estrategia en sí misma es insuficiente para el desarrollo -si es que por desarrollo queremos decir aumentar el bienestar de la mayoría de la población. Esto puede ilustrarse aún más de una manera empirica burda tomando como estimaciones futuras de $s$ y $k$ los valores más favorables encontrados por Kuznets que han prevalecido durante el último siglo en los diez países industriales que él estudió. Estos valores fueron $k=3$ y $s=22 \%$, ambos para el Japón de la posguerra (Kuznets, op. cit., p. 250). Sabemos que $p$ se aproximará a $4 \%$ a medida que la tasa de mortalidad disminuya y mientras la tasa de natalidad permanezca constante. De esta manera, tenemos que

$$
r=\frac{22}{3}-4=3.3 \%
$$

que ya habíamos visto era insuficiente para contrarrestar la tasa de reproducción de la clase baja y la proletarización general de la población. Además es muy dudoso que aun con la disciplina famosa de los japoneses se haya logrado tal valor de $s$ (y de $k$ ) si no hubiera sido por su política de población drástica que partió la tasa de natalidad a la mitad en sólo diez años, de 34 por mil en 1947 a 17 por mil en 1957 (Ohlin, op. cit., p. 68). No es accidental que el país industrial con el valor de $s$ más grande del mundo y el de $k$ el menor hubiera experimentado al mismo tiempo la declinación de $\boldsymbol{p}$. más impresionante del mundo. Por ello, aun suponiendo que el Nordeste pudiera igualar los valores de $s$ y $k$ del Japón, y hacer esto sin la ayuda de una política de población, no se detendría "de modo alguno el proceso de proletarización.

Pero, si el efecto económico de la política de población es tan fuerte, ¿por qué no ha sido adoptada? y ¿por qué es aún fuertemente rechazada? Una razón muy importante es simplemente la falta de información y de comprensiôn de los argumentos económicos, aunados a la inercia natural. Pero esto dista mucho de ser la historia completa. Para entender el resto debemos dirigirnos al meollo ideológico de la situación.

las comunidades que viven de la agricultura tradicional, "pero es la única fuerza con suficiente poder para hacer que tales comunidades cambien sus métodos y que a largo plazo se transformen en sociedades mucho más productivas y avanzadas". Ésta es realmente una afirmación increíble. ¿Debemos creer que toda la modernización agrícola ha resultado de la presión demográfica? ¿Por qué no son la agricultura de China o de la India más modernas que la de los Estados Unidos, el Canadá o Australia? ¿Es la presión de la población realmente tan fuerte? No lo ha sido en la India. El reto de las tasas de natalidad elevadas ha sido a lo largo de la historia aligerado por la respuesta rápida de las tasas de mortalidad elevadas más que por la difícil respuesta de la modemización - "no matarás, pero no lucharás oficiosamente para sobrevivir". El uso que hace Clark del término "a largo plazo" bien merece la aplicación de la famosa afirmación de Keynes de que "a largo plazo todos habremos muerto", porque de hecho la respuesta común a corto plazo al problema de la explosión demográfica es la elevación de la tasa de mortalidad, no la modernización de la agricultura. Esta última es poco común aun como respuesta a largo plazo. 


\section{LA IDEOLOGÍa DEL PROBLEMA DE LA POBLACión}

Como Ohlin ha dicho:

Las discusiones de los problemas de la población tocan inevitablemente las esferas íntimas de la vida al igual que las últimas: nacimiento, procreación y muerte. También evocan seductoramente nociones simples y en ocasiones contradictorias sobre el destino colectivo: una tasa decreciente de crecimiento de la población evoca la perspectiva de la decadencia y la extinción; mientras que una creciente parece reforzar la tribu o la nación, pero las cantidades excesivas llevan a la inanición y al hambre. Tales ideas básicas han dominado el pensamiento popular en el pasado y su influencia permanece hoy en día. ${ }^{4}$

Uno de los argumentos más socorridos es el de la impracticabilidad de "ejercer" compulsivamente el control natal. Nuestra discusión se refiere sólo al control voluntario. Lejos de limitar la libertad de nadie, la idea es extender a la clase baja la misma opción disfrutada por la clase alta en cuanto a limitar y espaciar su progenie.*

Como lo hace notar Rubens Costa:

Es bien conocido por todos que en nuestro país no existe en la práctica control oficial alguno sobre la venta de contraceptivos. De hecho, muchas familias de las clases media y alta limitan sus nacimientos. Pero las familias urbanas de bajos ingresos y las rurales no tienen ni los medios ni la información para controlar el número de hijos que desean tener. Por ello sucede que los que mejor pueden alimentar, educar y preparar a sus hijos para la vida son aquellos que tienen menor número de ellos, de lo cual resulta un deterioro continuo en la composición de la población.48

La relación entre "proletariado" (literalmente, aquellos con mucha descendencia) y "proliferación" es familiar en cualquier lengua, y es aún más aparente en portugués y español ("prole", "proletariado"). Caldas Aulete, el diccionario autorizado del portugués, define "proletario" como el "ciudadano de la clase más baja de gente, que es la clase cuyos miembros, pobres y exentos de impuestos, eran útiles a la repúbtica sólo para la procreación de niños" (el subrayado es mío). Aunque éste es el sentido romano antiguo de la palabra, no es de manera alguna obsoleto, y como se mostrará en lo que sigue, es más pertinente al Nordeste que el significado marxista más reciente.

Una reflexión muy exacta de la opinión pública en el Nordeste es la proporcionada por Rachel de Queiroz, una de las más sobresalientes

47 Ohlin, op. cit., p. 31.

* Finalmente cualquier tasa positiva de crecimiento llevará a la población a un tamaño imposible, de tal modo que a muy largo plazo se hará necesaria una tasa de cero. Como las preferencias usuales por 3 ó 4 hijos implican una tasa de crecimiento positiva, en el futuro tendrán que ser impuestas algunas condiciones restrictivas de la voluntad pura. Llevar esto a discusión antes de que los defensores de la libertad pura hayan ganado es como poner el carro enfrente del caballo.

48 Rubens Costa, "Necessidade de uma política populacional como parte da política de desenvolvimento", Jornal do Brasil, octubre 27, 1967. 
escritoras y de las ciudadanas más respetadas en la región. Ya que los puntos de vista de una eminencia literaria no sólo reflejan sino que también ayudan a formar la opinión pública, dichos puntos de vista tienen el valor de cien encuestas para averiguar el pensamiento de la comunidad. Por ello la citaremos ampliamente: ${ }^{49}$

...Tengo mis prejuicios en contra del control natal. Pues bien, ¿dónde estaría yo si mis padres lo hubieran practicado?

...Desde un punto de vista nacional y humano uno puede pensar en muchos argumentos que indiquen que esta clase de presión internacional que colocan sobre nosotros para limitar el control natal de los brasileños, no sólo es impertinente sino sospechosa.

¿Qué lógica puede haber en las campañas dirigidas a limitar el nacimiento de brasileños si a la vez tratamos de aumentar la población con inmigrantes europeos? ¿Significa esto que uno vuelve a la vieja tesis del conde Gobineau, del doctor Goebbels y de otros racistas, de acuerdo con quienes nuestra población está compuesta por mestizos degenerados que deberían ser reemplazados por europeos blancos?

La totalidad de la zona amazónica está vacía, desierta e inexplorada. ¿Qué población tiene Mato Grosso en relación con su superficie? y Goiás, y Pará y Amapá... No hay un estado en el Brasil, ni siquiera Ceará, que pueda calificarse de sobrepoblado.

El Brasil, en contra de lo que dicen sus amigos de ocasión y benefactores mezquinos, tiene gran cantidad de espacio para sembrar y criar ganado para sostener a sus niños. Quien quiera ayudarnos, que lo haga en este sentido y no tome ventaja de nuestras dificultades presentes para comprar a un precio vil lo que producimos.

...¿¿sería la China Roja capaz de tener el poder y la fuerza para enfrentarse a una coalición de casi la totalidad del mundo si no fuera por el tremendo capital representado por su población inmensa?

Dejad crecer a nuestrạ población... y no prediquen el suicidio nacional ante el temor de carecer de alimentos.

El amplio Amazonas con su densidad de población de menos de una persona por kilómetro cuadrado se ofrece usualmente como una evidencia concluyente de que el Brasil no tiene problema de población. Esta es una falacia popular. El desierto del Sahara tiene todavía menos gente por kilómetro cuadrado, y no obstante nadie lo considera subpoblado. Además, un medio tan hostil como el Amazonas es más fácil de ser conquistado por adultos educados y competentes técnicamente que por una progenie ilimitada de analfabetos hambrientos. Pero aun cuando el Amazonas fuera una planicie templada y fértil, la consideración pertinente es la tasa de crecimiento de la población, no el tamaño absoluto o la densidad espacial en un momento dado. Un aumento rápido de la cantidad de personas tiene costos de oportunidad en términos de la calidad de la gente. Si se desean estándares de calidad mínimos, una manera de auxiliar el logro de estos estándares es claramente reducir el aumento cuantitativo.*

49 Rachel de Queiroz, "O contrôle da natalidade", O Cruzeiro, mayo 27, 1967.

* Esta falacia de fijarse sólo en la densidad y de rechazar la tasa de crecimiento es cometida aún en las altas esferas - por ejemplo, Richard Nixon (citado en el Jornal do Brasil, 5/14/67): "Ésta [el control de la población] sería una posición falsa en este país, con superficies enormes por ser colonizadas. Realmente, el Brasil necesita desarrollar sus recursos naturales y aumentar su tasa de nata- 
Tenemos información suficiente para extraer algunas conclusiones. Mientras que los argumentos de la sección II en favor del control de la población suponen que la meta es maximizar el ingreso per capita (o mejor aún, el modal), queda claro que detrás de los puntos de vista que acabamos de citar está la meta de maximizar el poder y el prestigio de la nación -esto es, el ingreso total, no el per capitia.

Es interesante notar que los liberales del laissez-faire, que quieren dejar lo más posible de la vida económica a la regulación automática, han hecho usualmente una excepción con el caso de la población y han señalado consecuencias dramáticas si ésta no es controlada. ${ }^{50}$ Por el contrario, los planificadores y los autoritarios han deseado controlar todo salvo la población. El desprecio de Marx contra Malthus fue casi ilimitado, y los marxistas han considerado generalmente que la reforma socialista y el control de la población son alternativas incompatibles para elevar al proletariado.* Esta paradoja se resuelve fácilmente si se replantean las categorías a lo largo de las líneas más fundamentales del individualismo y el colectivismo. Los liberales individualistas desean proteger el valor del individuo de la depreciación resultante de la emisión de demasiados individuos, a la vez que de la intervención autoritaria del Estado. Los colectivistas se interesan más por el total, y un individuo más acrecienta el poder total en el sentido de que aumenta el rebaño. Más aún, un número moderado de personas puede ser considerado individualmente, pero un número inmenso sólo puede serlo colectivamente. Así, la explosión demográfica ajusta perfectamente tanto con el dogma colectivista como con las tácticas revolucionarias de crear presiones sociales en los países en desarrollo. Por ejemplo, la revista brasileña socialista Problemas da Paz e do Socialismo reconstruye un debate de tijera y pasta entre los expertos en la población mundial, al referirse al problema "¿Existe la amenaza de la sobrepoblación?" Está claro que la respuesta negativa es

lidad para aumentar el valor de su territorio propio". El presidente Costa e Silva también comete la misma falacia en una carta al papa Pablo VI, ensalzando la encíclica Humanae Vitae (Jornal do Comercio, 8/13/68): "En nombre del pueblo y del gobierno del Brasil expreso a Su Excelencia la dicha y gratitud ocasionada por la encíclica en la cual la voz suprema de la Iglesia da su condenación apropiada a los métodos anticristianos de control de los nacimientos. Como dirigente de un país al que todavía le preocupa ocupar más de la mitad de su territorio, y expuesto aún a los riesgos de una densidad de población incompatible con las necesidades globales del desarrollo y la seguridad, aplaudo tan notable documento. Lo aplaudo no sólo por nuestra fe indestructible en los diez mandamientos cristianos, sino también por constituir los fundamentos morales y de la estrategia de la política seguida por el Brasil en su jornada hacia el progreso material y espiritual de su gente, y como contribución a la paz y la armonía entre las naciones".

Uno podría sostener que la población óptima del Brasil es dos veces el monto de la presente sin contradecir en manera alguna el argumento principal de la sección II. Pero existe una gran diferencia entre duplicar la población a una tasa anual de $1 \%$ y hacerlo a una tasa anual de $3 \%$-iprobablemente la misma diferencia que existe entre aumentar o disminuir el nivel de vida de la mayoría de la población!

50 Este argumento es presentado por Camargo, op. cit.

* Cf. el economista marxista R. L. Meek, Marx and Engels on Malthus, Londres, Lawrence y Wishart, 1953, p. 47. "Si los hechos sociales de principios del siglo XIX hubieran estado esencialmente englobados en la controversia entre Malthus y Ricardo, tal vez sería justo decir que los de nuestros tiempos están considerados entre los malthusianos y los marxistas." 
la que "gana" y el tema central es que "es necesario defender las poblaciones del capitalismo y no al capitalismo de las poblaciones". ${ }^{51}$ Uno escucha con frecuencia también el slogan: "un niño hambriento más ahora significa un guerrillero más de mañana".

Los escritores malthusianos de la escuela clásica se han inclinado a poner énfasis en aquellas implicaciones de la teoría de Malthus que eran desfavorables a la reforma social -por ejemplo, la redistribución del ingreso entre los pobres permitirá sólo que exista un número mayor de personas al mismo nivel miserable de subsistencia, y es por ello una mala política. Esto tranquiliza la conciencia de los ricos y por tal razón ha dado al malthusianismo una mala connotación entre los marxistas y los liberales. Hay, sin embargo, una implicación más radical del análisis de Malthus, que puede inclusive ser expresada en términos marxistas. Marx nos dice que el capital no es una cosa sino una relación social:

...la propiedad en dinero, medios de subsistencia, máquinas y otros medios de producción no convierte al individuo en capitalista si no es por la existencia de su correlativo, el asalariado, el otro hombre que es impelido a venderse bajo su propia voluntad.

...el capital no es una cosa sino una relación social entre personas, establecida por la instrumentalidad de las cosas. ${ }^{52}$

De la misma manera, la mera propiedad de la tierra no hace de un hombre un latifundista si faltara su correlativo: el trabajador agrícola de subsistencia. La abundancia de "correlativos" es una condición necesaria para que prevalezca una clase privilegiada propietaria. Arthur Lewis señala también que:

El hecho de que el nivel de salarios en el sector capitalista dependa de las percepciones del sector de subsistencia es en ocasiones de inmensa importancia, ya que su efecto es que el capitalista tenga interés directo en mantener baja la productividad de los trabajadores de subsistencia. 53

Nótese que la observación de Lewis implicaría un conflicto entre el capitalista industrial y el latifundista, un conflicto, por añadidura, que puede ser evitado, ya que el capitalista está interesado solamente en mantener baja la productividad marginat (o la productividad me-

51 E. Arab-Ogli, "Existe a ameaça da superpopulação?", Problemas da paz e do socialismo, agosto, 1961, Río de Janeiro, p. 71. El autor es un notable escritor soviético sobre temas de población, y el artículo puede tomarse como un buen ejemplo de la propaganda soviética en los países subdesarrollados. Es increíble que Arab-Ogli haya podido interpretar equivocadamente al demógrafo francés Alfred Sauvy, en el sentido de hacerlo aparecer como oponente a la política de población y que aconseja "No se preocupen." Esta es una caricatura de los puntos de vista balanceados y juiciosos presentados por Sauvy en Fertility and Survival: Population Problems from Matthus to Mao Tse-Tung (Nueva York, Criterion Books, 1961). Sin embargo, en artículos recientes de Arab-Ogli y de otros demógrafos soviéticos se han tomado puntos de vista menos dogmáticos sobre el problema de la población en los países subdesarrollados, e inclusive admiten que el control natal puede ser ayuda para el esfuerzo por el desarrollo. (Véase "Soviet Population Theory from Marx to Kosygin", Population Bulletin, Vol. XXIII, Núm. 4, octubre, 1967.)

52 Marx, El capital, Cap. 23 ,

53 W. Arthur Lewis, loc. cit. 
dia, según la que gobierne los salarios de subsistencia). Esto interesa también al latifundista y es logrado en forma muy simple al permitir al proletariado dar cabida a su orgullo y proliferar; mientras más trabajadores haya, los productos marginal y medio y los salarios serán menores, y existirán menos posibilidades de conflicto entre los capitalistas y los latifundistas. En la medida en que el proletariado correlativo sea menos numeroso, el peso de la mezquindad de la naturaleza deberá ser en parte soportado por los capitalistas y los latifundistas que tendrán que pagar salarios más elevados y pasarla con menos siervos. Por ello, predicar el control de los nacimientos entre el proletariado es un ataque al status quo, y no tiene relación con el lado apologético del malthusianismo. Aunque Lenin se opuso al "neomalthusianismo" como política social, estuvo en favor de la circulación libre de la información sobre el control de los nacimientos y la abolición de las leyes que penaban el aborto. ${ }^{54}$ Así, si fuera tácticamente viable llevar a cabo el control de los nacimientos los comunistas podrían encontrar apoyo textual; pero las tácticas revolucionarias oportunistas invocan el reforzamiento de la presión de la miseria y distraen la atención de cualquier alternativa que no sea la revolución comunista. Aunque parezca extraño, se acusa de hipocresía a los países occidentales cuando abogan por el control de la población en los países subdesarrollados. Pero debe notarse que los países occidentales mismos, en este caso, practican lo que predican, mientras que el bloque comunista predica el crecimiento ilimitado, pero en casa practica la limitación. Es bien sabido que en Hungría la tasa de abortos excede por mucho la tasa de natalidad. La presión pro-revolucionaria originada por una tasa de natalidad elevada proviene no sólo de la cantidad de población sino de la composición por edades de ésta. Una población más joven es más volátil y más fácil de manipular.

El concepto marxista de proletariado (el trabajador industrial desposeído cuya existencia depende de la venta de su fuerza de trabajo) es pertinente en el Nordeste, pero el sentido romano original (productores de hijos para la república) se apega mucho más a las características de la clase más baja de la sociedad en esa región. Después de todo, la industria apenas representa el $12 \%$ del producto total. Además, aplicar una ley capitalista de "población con excedentes relativos" a una sociedad esencialmente precapitalista va mucho contra el espíritu del pensamiento de Marx, en el cual "todo modo de producción histórico tiene sus propias leyes especiales de población, válidas históricamente dentro de sus límites' exclusivamente". ${ }^{55}$ Los nordestinos proletarios son explotados a través de su papel en la saciedad análoga a una manada de reses que es valorada sólo en términos de su tamaño total, no en los del bienestar individual de sus miembros. Mientras que la explotación en el sentido marxista ha atraído mucha atención favorable, "la explotación romana" ha pasado desapercibida. No es extraño que en el Nordeste el clero católico con

5.4 Ver Sidney Coontz, op. cit., Cap. 5, nota al pie, p. 53.

55 Marx, El capital, Vol. I, Cap. XXV. De acuerdo con el padre Melo, vicario de Cabo, "el progreso en el Nordeste está siendo efectuado bajo un subcapitalismo... el cual es... mucho peor que el capitalismo ya que éste mantiene al menos sus hombres-máquina, mientras que el primero ni siquiera hace esto". (Jornal do Brasil, diciembre 24, 1967.) 
conciencia social tienda hacia la izquierda, ya que su dogma hace más fácil simpatizar con un proletariado marxista que con uno romano. No obstante, este último es más congruente con la realidad del Nordeste. La explotación vía propiedad monopólica de los medios de producción es más obvia que la explotación vía "propiedad" monopólica de los medios de limitación de la reproducción, pero ésta no es más efectiva, ni más degradante. La propiedad por parte de la oligarquía tanto de los medios de la producción como de los medios de limitación de la reproducción lleva a una explotación en el sentido marxista y romano simultáneamente, con el resultado de que la población proletaria, al igual que cualquier población animal, está limitada por su riqueza agregada, mientras que la población de la clase alta tiene la característica distintivamente humana de estar limitada por su nivel de vida.

La explotación romana * es también un concepto teóricamente más cuerdo que la explotación marxista, ya que esta última está enredada innecesariamente con la teoría del valor-trabajo, mientras que la primera depende para su operación sólo de las leyes de la oferta y la demanda, y del hecho sólido de que la clase baja es más prolífica. El hecho de que Marx mismo (en oposición a los marxistas) haya tenido cierta simpatía por la explotación romana puede observarse en la cita siguiente:

De hecho, no sólo el número de nacimientos y defunciones, sino también el tamaño absoluto de la familia, están en proporción inversa al nivel de los salarios, y por lo tanto a la cantidad de medios de subsistencia de la cual disponen las diferentes categorías de trabajadores. Esta ley de la sociedad capitalista sonaría absurda a los salvajes, o aun a los colonialistas civilizados. Trae a nuestra mente la reproducción ilimitada de los animales débiles individualmente y constantemente acosados. 50

El énfasis colectivista (útil a la república) en el concepto de explotación romana puede ser entendido mejor si se tiene siempre en mente que no todos los miembros de la colectividad son iguales. La oligarquía y la clase que constituye la opinión pública practican ya el control natal en el Nordeste. Como hemos visto, el hecho de que las masas no lo hagan significa que habrá siempre una oferta ilimitada de trabajo con salarios bajos para el desarrollo de la industria de la oligarquía, y para trabajar en las fazendas de la oligarquía, y para proveer de sirvientes los hogares oligarcas y de babas que cuiden los hijos

* El término "explotación romana" tiene varias justificaciones. Primeramente el sentido romano antiguo de la palabra "proletariado", ya discutido. Segundo, la limitación consciente del tamaño de la familia por parte de los patricios romanos (véase Sidney Coontz, op. cit., nota al calce, p. 18, Cap. 7). Tercera, y más reciente, la oposición católico-romana tradicional al control de la natalidad, a la que los protestantes se han referido como simplemente una estrategia para sobrepasarlos en número. Véase también Edward Gibbon, The Decline and Fall of the Roman Empire, Cap. 2: "la fuente de suministro externo [de esclavos] fluyó con mucha menos abundancia, y los romanos fueron reducidos al más suave pero más tedioso procedimiento de la propagación. En sus familias numerosas, y en particular en sus propiedades, estimularon el matrimonio de sus esclavos". Favorecer la propagación de "esclavos asalariados" es todavía una política atractiva para los oligarcas:

56 Marx, El capital, Vol. I, Cap. XXV. 
de éstos. No debemos tampoco dejar pasar el hecho de que los valores de la tierra tienden a elevarse con la población, de modo que la clase terrateniente disfruta de una ganancia de capital a la vez que de fuerza de trabajo barata. Una manera importante de complementar el control de la natalidad sería instituir un impuesto sobre la tierra, especialmente sobre la tierra ociosa, que tendría la ventaja doble de fomentar el uso de la tierra y reducir su precio, desalentando así la inversión especulativa e improductiva en la tierra, fenómeno tan común en los países inflacionarios. Asimismo, los beneficios de la tierra podrían utilizarse para la construcción de escuelas para los analfabetos (algo así como el $80 \%$ de la población), y para financiar la educación sobre el control natal.

Puede hacerse un paralelismo histórico interesante entre las actitudes de los oligarcas nacionalistas brasileños de hoy y los nacionalistas y mercantilistas ingleses del siglo xvIr. De acuerdo con el estudio excelente de E. S. Furniss, The Position of the Laborer in a System of Nationalism, podemos ver fácilmente cómo las metas de los mercantilistas llevaban implícito el deseo de un proletariado grande. Con más trabajadores, más era posible producir para exportar y más fácil era vender el producto, ya que los salarios y los costos de la mano de obra eran mantenidos bajos mediante la oferta abundante de trabajadores, quienes por supuesto no consumían lo importado más allá del ínfimo necesario. El resultado deseado de un excedente grande en la balanza de pagos (que fue considerado la verdadera riqueza de la nación) fue así asegurado mediante un proletariado numeroso. De aquí la conclusión tan natural para un mercantilista y tan extraña a los oídos modernos, de que para tener una nación rica es necesario tener un número muy grande de gente muy pobre. En las palabras claras de Peter Chamberlen (citadas por Furniss, p. 25):

Ésta podría ser una nota a todos los hombres, especialmente a los estadistas, para que no vean en los pobres una carga sino el más rico tesoro de una nación, si son utilizados bien y con diligencia. Esto es lo más manifiesto si consideramos primero, que aunque aquéllos se multiplican más rápidamente que los ricos, no se alimentan y se visten a sí mismos sino que los ricos son alimentados y vestidos y se enriquecen más con lo que obtienen del trabajo de los pobres como excedente de lo que necesitan éstos para su subsistencia. Segundo, que los pobres llevan una carga mayor de impuestos en la ciudad y cualquier otro lugar. Porque los ricos o bien acaban con lo que obtienen del trabajo de los pobres o (lo que es peor) permiten a éstos morir de hambre en su búsqueda de empleo.

El punto sobresaliente de similaridad entre los mercantilistas y los nacionalistas brasileños (de izquierda o de derecha) es que ambos son nacionalistas, influidos en muy poco por las premisas liberales individualistas (sesgos) de la economía moderna. La meta nacional de los mercantilistas era maximizar el excedente de la balanza de intercambio, mientras que el de los nacionalistas brasileños es maximizar la tasa de crecimiento del sector industrial capitalista de su economía. Para lograr este último fin la inversión y las utilidades deben ser altas y el consumo bajo, lo cual en turno lleva a una política 
de salarios bajos garantizados por la existencia de muchos trabajadores. Furniss hace hincapié en que para el nacionalista, "es la forma de los bienes económicos, no su valor en un mercado competitivo, lo que da a la riqueza su significado. Considerada así, la riqueza nacional está compuesta sólo por aquella parte de los bienes económicos de un país que brindan servicio, directa o indirectamente, en la prosecución de los propósitos y las metas de un grupo". Para los nacionalistas ingleses del siglo XIX la forma deseable de la riqueza era el excedente en la balanza comercial en oro; para los nacionalistas brasileños del siglo $\mathrm{xx}$ la forma deseable es la industria capitalista moderna - para ambos, un proletariado abundante es un medio para llegar a un fin. Los fines tienen en común que, en sus contextos históricos, ambos son considerados el ingrediente crucial del poder nacional.

El concepto de explotación romana es sugerido, y aun recomendado, por el escritor brasileño que se cita en seguida, quien da también evidencia que apoya las afirmaciones anteriores acerca de las diferencias de clase en la reproducción -evidencia de una índole de la que no puede sospecharse la más ligera desviación en favor del control de los nacimientos:

La contribución de esta clase [la burguesía] al desarrollo demográfico es ridículamente pequeña.

La clase media... se rebela y está asfixiada por el proceso de proletarización... al cual se resiste con bravura, aunque sin éxito. $Y$ cuando ocurre un embarazo involuntario, algunos de los miembros de la clase media recurren al arma de Herodes...

Sólo la clase más baja o proletariado produce, y produce escandalosa y anormalmente. Los investigadores de escritorio no se dan cuenta tal vez de que estos hombres que reciben salarios mínimos, salarios de hambre, ofrecen una gran contribución a la nación... dos brasileños por año ( $i c$ ), pareja por pareja, uno en enero y uno en diciembre.

A la vez que reconozco la angustia financiera en la que vegeta el proletariado, y la marginalización en la que está sumergido, creo que es inmoral aconsejar a una criatura de ese tipo la práctica del control de los nacimientos. Creo que es una gran transgresión contra las leyes del hombre y de Dios sugerir las prácticas anticonceptivas a hombres que no hacen más que trabajar y dormir. Ellos son como los lirios del campo y las aves del cielo... ellos nacen, crecen y producen, con la fe en que Dios les dará vestido en conformidad con el frío. 57 (Las cursivas son mías.)

Este escritor habla de las leyes de Dios y de los lirios del campo, pero realmente está diciendo lo que Peter Chamberlen dijo: que los hombres que no hacen más que trabajar y dormir son criaturas manejables, y que deberíamos mantener a la nación bien abastecida de ellos.

Hay personas en el Nordeste que abogan valientemente por la política de población, tal vez los médicos más que los economistas. Sin embargo, Rubens Costa, presidente del prestigiado Banco del Nordeste,

57 Domingos Gusmão de Lima, "Os lírios do campo e as aves do céu", O Povo, Fortaleza, diciembre 30 y 31, 1967. ¡Referirse al prójimo como si fuera simplemente un "lirio del campo o un ave en el cielo" es una interpretación más bien forzada del sermón de la montaña! 
ha sido citado muchas veces. En su prefacio a una discusión sobre políticas de población, él dice que el tema está

...cargado de emoción y controversia debido a las presentaciones inadecuadas de personas que no han pensado en la materia y que no se han tomado la molestia de informarse antes de emitir opiniones, y por otras que, por motivos inconfesables, buscan crear un alboroto y generar una atmósfera impropicia al debate constructivo, serio y de alto nivel.58 (Las cursivas son mías.)

No es necesario decir que el problema de la población no se limita al Nordeste, al Brasil, o al Tercer Mundo. Es un problema mundial cuya solución es obstruida seriamente por la mentalidad nacionalista de todos los países, así como por las divisiones raciales y de clase dentro de ellos; como es, por ejemplo, la oposición nacionalista negra al control de la natalidad en los Estados Unidos. La explosión demográfica es también la razón principal de la ampliación de la brecha en los ingresos per capita de las naciones ricas y las pobres y no es por lo tanto extraño encontrar efectos similares sobre las diferencias de clase dentro de naciones o regiones. ${ }^{59}$

Esta sección ha sido más polémica de lo que algunos pensarán que debe ser el trabajo científico. Pero ya que nuestro análisis económico objetivo nos llevó a esperar aceptación amplia de la política de población, se hizo necesario explicar su rechazo vehemente a otro nivel de discusión, denominado claramente "ideológico".

Mientras que es posible esperar que el Nordeste esté en el umbral de una época de desarrollo nueva, y que la política de población sea aceptada con el tiempo, debemos reconocer junto con Ohlin que,

...probablemente la carrera contra el tiempo es más urgente que contra el espacio... Dado el tiempo, no hay duda de que la economía mundial daría cabida a poblaciones varias veces más grandes que las presentes. Con tiempo, el capital puede ser formado; con tiempo las reformas sociales serán llevadas a cabo. Pero en el presente estado de cosas el mundo en desarrollo se enfrenta a un período de transición de duración incierta en que el tiempo será muy corto. La mortalidad continuará en descenso, y la población crecerá a tasas que absorberán el grueso de los recursos que de otra manera se orientarían a costear la demanda impostergable de modernización y desarrollo. Nacerán millones fuera de fase con la historia. 60

En ninguna otra parte es más cierto lo anterior que en el nordeste del Brasil. $\mathrm{Y}$ en ningún otro lugar es resistido tan vigorosamente el control natal.

58 Rubens Costa, "Necessidade...", loc. cit. Una discusión interesante de las actitudes de los intelectuales latinoamericanos respecto de la población aparece en el artículo de J. Mayone Stycos en Population Dilemma in Latin America, J. Mayone Stycos y Jorge Arias (compiladores), Washington, Potomac Books.

59 Robert E. Baldwin, Economic Development and Growth, Nueva York, John Wiley and Sons, 1966, p. 8. "En el lapso 1957-58 a 1963-64, las naciones menos desarrolladas mantuvieron una tasa de crecimiento anual del producto nacional bruto de $4.7 \%$ en comparación con $4.4 \%$ en las economías desarrolladas. La brecha en el ingreso per capita se amplió debido a que la población creció a sólo $1.3 \%$ anual en los países desarrollados comparado con un $2.4 \%$ anual en las economías menos desarrolladas."

60 Ohlin, op. cit., p. 131. 


\section{APÉNDICE}

Aunque es imposible hacer cálculos exactos con datos tan inexactos, podemos, sin embargo, afinar algunas nociones, mostrar las relaciones lógicas entre nuestras variables principales y cerciorarnos de que las estimaciones numéricas, tomadas juntas, no llevan a situaciones absurdas o a imposibilidades serias.

Considérese primero la distribución probable del ingreso y la división de clases en el Nordeste, como se muestra en seguida.

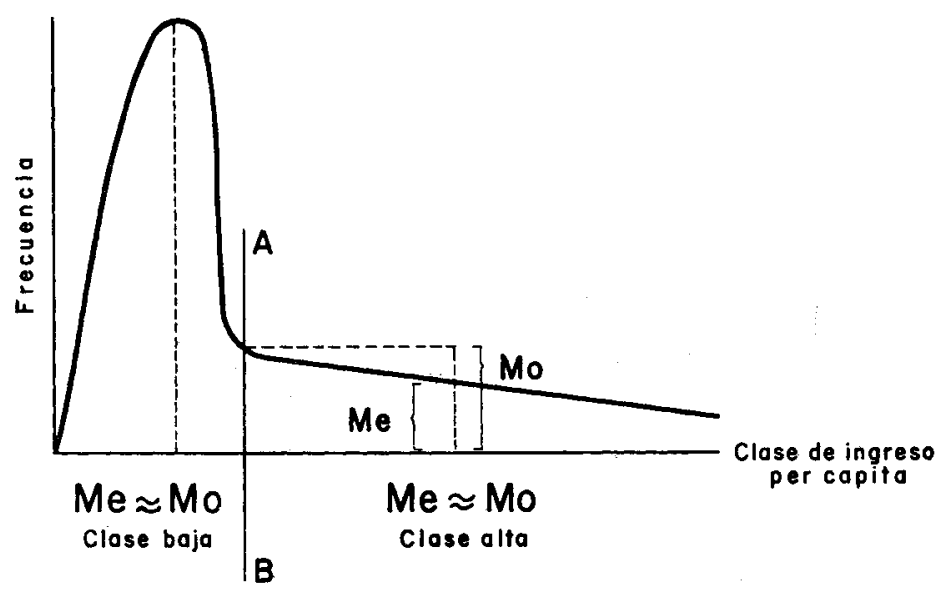

DISTRIBUCTón PROBABLE DEL INGRESO EN EL NORDESTE DEL BRASIL

La línea $A B$ separa la distribución asimétrica en dos subdistribuciones: la de las clases baja y alta. Dentro de cada distribución la media respectiva es una buena aproximación a la moda. Para la distribución total la moda es más parecida a la media de la clase baja. Durante una generación ( 25 años) la clase baja aumenta según un factor de 4 ( 8 niños divididos entre 2 padres); la clase alta hace otro tanto según un factor de 2 (4 niños divididos entre 2 padres). 1

Para que esto se pueda ver con mayor claridad, considérense las condiciones en que una población crece, bajo los siguientes supuestos: la edad promedio de los padres al nacimiento del primer hijo es de 25 años; cada pareja tiene 4 hijos (que sobreviven para a su vez tener más) y todas las personas mueren a la edad de 50 años. Esta población crecerá como se muestra en el esquema que sigue, en el que los números entre paréntesis representan la edad $(0=$ hijos, $25=$ padres, $50=$ abuelos $)$, y el número fuera del paréntesis es la cantidad de personas de esa edad particular.

Esta población, consistente en hijos y padres (véanse los rectángulos) se duplica claramente cada 25 años -este factor de duplicación representa la proporción de hijos a padres, 4/2. Nótese que podríamos incluir los abuelos

1 Se supone ahora que cada clase consiste enteramente de familias idénticas, típicas de esa clase. También las estimaciones de 4 y 8 hijos se refieren a las que sobreviven a la mortalidad infantil. El número de nacimientos sería mayor especialmente para la clase baja. 
(y tantas generaciones con vida como deseáramos), y la población total se duplica, no obstante, cada 25 años por la razón de que cada grupo de edad componente se duplica cada 25 años.

El ingreso total de cada clase, el cual crece al $6.5 \%$ anual, aumentará según un factor de 4.8 por generación. Por lo tanto, el ingreso per capita de la clase más baja crecería a un factor de $4.8 / 4=1.2$ por generación, mientras que el ingreso per capita de la clase más alta haría otro tanto según un factor de $4.8 / 4=2.4$. Si se toma en cuenta que la elevada probabilidad de que el ingreso total de la clase baja crezca a tasa menor, y el de la alta a tasa mayor que el $6.5 \%$ anual que se supuso, podemos considerar que el ingreso per capita de la clase baja permanece constante (o tal vez dis-

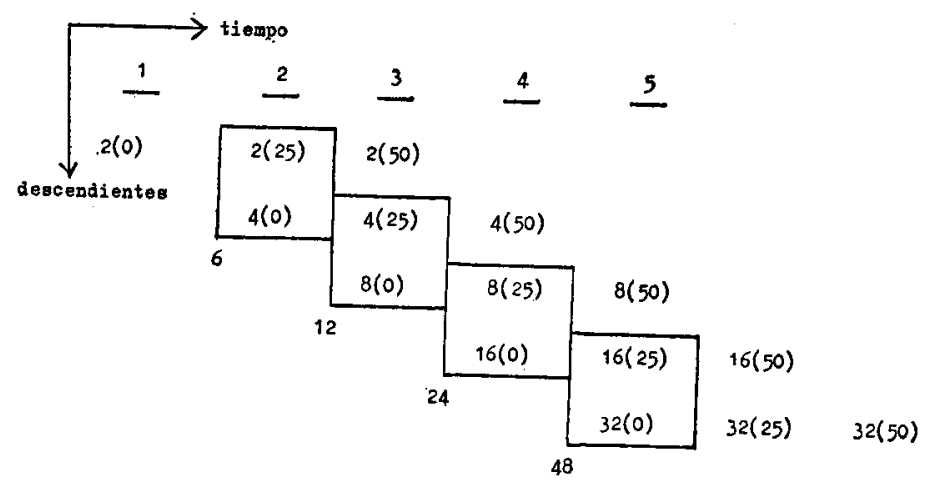

minuye), y el de la clase alta aumenta a razón de más de 2.4 veces por generación. En términos del diagrama de distribución presentado antes, la parte de la curva referente a la clase baja se desplaza verticalmente hacia arriba según un factor de 4 cada generación, mientras que permanece constante en sentido horizontal o puede hasta desplazarse un poco hacia la izquierda. La parte de la curva referente a la clase alta se desplaza hacia arriba según un factor de 2 y horizontalmente hacia la derecha según un factor de 2.4 por generación. En consecuencia, en el transcurso del tiempo la moda constante se hace más y más "modal" - esto es, más y más representativa de la población total.

Es interesante intentar insertar todas las variables y las estimaciones numéricas conjuntamente en un solo esquema y ver qué resulta. Para lograr esto, podemos acudir a la siguiente relación de "interés compuesto": 2

$$
(y \cdot R)^{1 / g}=1+p
$$

donde $R$ es la relación de reproducción, o, en forma burda, el número de hijos nacidos divididos por el número de padres, $g$ es la duración de una generación, o la edad media de las madres al nacimiento del primer hijo, $y$ es la población en reproducción como porciento de la población total y $p$ es la tasa anual de crecimiento de la población total.

Al aplicar la relación anterior a las poblaciones de las clases alta y baja, y tomar una media geométrica ponderada de las dos tasas de crecimiento anual resultantes, llegamos a la siguiente fórmula:

2 Ver Hannes Hyrenius, "Population Growth and Replacement" en la obra de Duncan y Hauser (compiladores), The Study of Population. 


$$
\log M_{g}=\frac{w \log (y \cdot R)^{1 / g}+w^{1} \log \left(y^{1} \cdot R^{1}\right)^{1 / g^{1}}}{w+w^{1}}=\log (1+p)
$$

$M_{a}=$ media geométrica de las tasas de crecimiento de las clases alta $\mathrm{y}$ baja;

$w$ = clase baja como proporción de la población total;

$w^{1}=$ clase alta como proporción de la población total;

$y=$ población en reproducción como porciento de la población total, para el caso de la clase baja;

$y^{1}=$ población en reproducción como porciento de la población total, para el caso de la clase alta;

$R=$ tasa de reproducción de la clase baja;

$R^{1}=$ tasa de reproducción de la clase alta;

$g$ = duración de una generación en años, clase baja;

$g^{1}=$ duración de una generación en años, clase alta;

$p=$ tasa anual de crecimiento de la población total (clases alta y baja).

Tenemos aquí una lista de las variables importantes de nuestro análisis, para la mayoría de las cuales contamos con estimaciones burdas. De acuerdo con la información censal, $p$ es $3.1 \%$. Otras estimaciones son más altas, y hemos visto que con la tasa de mortalidad descendente y la de natalidad constante, $p$ se aproximará a $4 \%$. Lo más que podemos decir con certeza es que $p$ es superior a 3 e inferior a 4 ; probablemente se acerca más al primer valor. A partir de $w, y, R$ y $g$ podemos obtener una estimación de $p$ independiente que también resultaría de entre 3 y $4 \%$ si nuestras estimaciones numéricas individuales son razonables.

$R$ y $R^{1}$ han sido discutidas previamente y su valor ha sido tomado como 4 y 2 , respectivamente.

Hemos tomado $g$ como de 25 años, basados más o menos en la observación ligera. La información sobre $g$ es extrañamente difícil de obtener, pero un estudio de Virginia Rodríguez, ${ }^{3}$ del Centro Latinoamericano de Demografía, ofrece datos para Argentina, Paraguay y Chile, y muestra el número medio de niños por madre por grupo de edad y nivel educacional de aquélla. Por interpolación, a partir de dichas tablas y diagramas, se puede calcular la edad de las madres correspondiente al punto medio del número promedio de hijos para las mujeres que ya pasaron de la edad reproductiva. En otras palabras, si el número total de hijos que tiene una mujer de cierta clase es 5, veamos entonces a qué edad una mujer de esa clase tiene su tercer hijo, y tomemos ésta como una estimación de g. EI intervalo que contiene este valor es entre cerca de 23 para los argentinos de bajo nivel educativo, de 30 para los argentinos de mejor nivel educativo, entre 26 y 27 para los chilenos de bajo y alto nivel educativo, y de 26 a 30 para los paraguayos en los niveles correspondientes. Mortara afirma que la duración de una generación en el Brasil es de 26 años. ${ }^{4}$ Éstas son estimaciones burdas basadas en datos inciertos, pero sugieren que nuestra estimación de $g=25$ o 26 es razonable. Tomemos el dato de Mortara de 26 años. Trataremos $g=g^{1}$ aunque una generación de la clase alta es probablemente más larga que la de la clase baja (lo cual significa que hemos probablemente subestimado las diferencias entre clases en las tasas de reproducción).

Para el caso de $w$ y $w^{1}$, las proporciones de ricos y pobres, podemos tomar una pista de las proporciones de alfabetos y analfabetos - 15 y $85 \%$, respectivamente. Ya que hay pocos pobres que sean alfabetos, pero práctica-

3 "Fecundidad diferencial según nivel de instrucción", mayo de 1967, serie C, Núm. 97, CELADE, Santiago de Chile.

4 Giorgio Mortara, Revista Brasileira de Estadistica, 1947-48. 
mente ningún rico es analfabeto, tomaremos para nuestra estimación: $w=90 \%$ y $w^{1}=10 \%$.

La variable $y$ representa el porciento de población (femenina) que nunca ha tenido hijos, y está determinada principalmente por la tasa de mortalidad previa a la edad reproductiva y la tasa de celibato permanente durante la edad reproductiva. Ya que nuestras estimaciones del número promedio de hijos por familia fueron basadas en los niños sobrevivientes a la mortalidad infantil (de un año de edad), nos gustaría conocer el porciento de mujeres de un año de edad que mueren antes de alcanzar la edad de, por ejemplo, 20 años. De acuerdo con una tabla de sobrevivencia preparada por G. Mor$\operatorname{tara}^{5}$ esta cifra sería de alrededor de $15 \%$ para São Paulo en 1930-32 (lo cual él considera indicativo del valor correspondiente a todo el Brasil para 1956). La tasa de celibato permanente puede ser estimada como el porciento de personas solteras que nunca contrajeron matrimonio mayores de 50 años, y de acuerdo con las cifras de Naciones Unidas ${ }^{6}$ esta tasa fue de $13.1 \%$ para todo el Brasil en 1950. Al agregar estos porcientos resulta un valor burdo de $30 \%$ de mujeres que no reproducen, o bien un $70 \%$ de mujeres que sí lo hacen. Así, nuestra estimación burda es $y=0.7$.

Después de sustituir estos valores en la fórmula, obtenemos:

$$
\log M_{g}=\frac{90(.7 \times 4)^{1 / 26}+10(.7 \times 2)^{1 / 26}}{100}
$$

y $M_{\sigma}=1+p=1.0376$ o bien $p=3.76 \%$, lo cual cae "entre 3 y $4 \%$ ". Esta correspondencia tan burda no demuestra que nuestras estimaciones conjeturadas de $R, w, y$ y $g$ sean correctas -queda mucho lugar para compensar los errores. Hemos dejado solamente de demostrar la hipótesis contraria de que nuestras estimaciones tienen implicaciones lógicas que son en alto grado inconsistentes con la información censal. Una refutación contra nuestra conjetura ha fallado; por lo tanto nuestra confianza en ella queda un tanto mejorada.

5 Giorgio Mortara, "The Development and Structure of Brazil's Population", en Demographic Analysis, Spengler y Duncan (compiladores), Glencoe, Illinois, Free Press, 1956, p. 663.

6 United Nations Compendium of Social Statistics, 1963, p. 63. 